Original Paper

\title{
(-)-Epigallocatechin-3-Gallate Inhibits Arsenic-Induced Inflammation and Apoptosis through Suppression of Oxidative Stress in Mice
}

\author{
Nan-Hui Yu, Haiping Peib Yong-Pan Huang ${ }^{\mathrm{c}, d}$ Yu-Fei Lid \\ aDepartment of Pharmacy, Changsha Hospital for Maternal and Child Health Care, ${ }^{b}$ Department of \\ Gastrointestinal Surgery, Xiangya Hospital, Central South University, 'Xiangya School of Medicine, \\ Central South University, Changsha, 'SChool of Medicine, Hunan Normal University, Changsha, Hunan, \\ China
}

\section{Key Words}

arsenic • (-)-epigallocatechin-3-gallate $(E G C G) \bullet$ Immunotoxicity • Oxidative stress • Apoptosis

\begin{abstract}
Background/Aims: Exposure to arsenic in individuals has been found to be associated with various health-related problems including skin lesions, cancer, and cardiovascular and immunological disorders. (-)-Epigallocatechin-3-gallate (EGCG), the main and active polyphenolic catechin present in green tea, has shown potent antioxidant, anti-apoptotic and anti-inflammatory activity in vivo and in vitro. Thus, the present study was conducted to investigate the protective effects of EGCG against arsenic-induced inflammation and immunotoxicity in mice. Methods: Serum IL-1 $\beta$, IL- 6 and TNF- $\alpha$ were determined by ELISA, tissue catalase (CAT), malonyldialdehyde (MDA), superoxide dismutase (SOD), glutathione (GSH), nitric oxide and caspase 3 by commercial kits, mitochondrial membrane potential with $\mathrm{Rh} 123$, mitochondrial ROS with 2',7'-dichlorofluorescin diacetate (DCFH-DA), apoptotic and necrotic cells and T-cell phenotyping with Flow cytometry analysis. Results: The results showed that arsenic treatment significantly increased oxidative stress levels (as indicated by catalase, malonyldialdehyde, superoxide dismutase, glutathione and reactive oxygen species), increased levels of inflammatory cytokines and promoted apoptosis. Arsenic exposure increased the relative frequency of the $\mathrm{CD} 8+(\mathrm{Tc})$ cell subpopulation (from 2.8 to 18.9\%) and decreased the frequency of $\mathrm{CD} 4+(\mathrm{Th})$ cells (from 5.2 to $2.7 \%$ ). Arsenic exposure also significantly decreased the frequency of $T(C D 3)$ (from 32.5\% to 19.2\%) and B(CD19) cells (from 55.1 to 32.5\%). All of these effects induced by $\mathrm{NaAsO}_{2}$ were attenuated by EGCG. Conclusions: The present in vitro findings indicate that EGCG attenuates not only $\mathrm{NaAsO}_{2}$-induced immunosuppression but also inflammation and apoptosis.
\end{abstract}




\section{Cellular Physiology Cell Physiol Biochem 2017;41:1788-1800

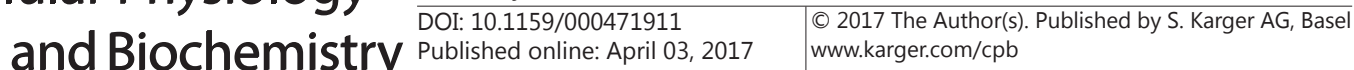 \\ Yu et al:: (-)-Epigallocatechin-3-Gallate Attenuates Arsenic-Induced Inflammation and Apoptosis}

\section{Introduction}

Arsenic is a toxicologically important compound that is widely distributed in the environment due to its natural existence and anthropogenic applications [1]. Arsenic exposure is associated with considerable human morbidity and mortality. There is accumulating evidence that chronic exposure to arsenic, even at fairly low levels, leads to increased risk of infectious diseases, such as polyneuritis, diarrhoea, and immunosuppression of the T-dependent antibody response [2, 3]. Moreover, arsenic exposure in individuals promotes the generation of reactive oxygen species and nitric oxide and is involved in the production of pro-inflammatory cytokines [4-6]. Elevated levels of interleukin-6 (IL-6) and tumour necrosis factor alpha (TNF- $\alpha$ ) produced by the immune system play an important role in the immune response. These factors deteriorate in arsenic-related dysfunction of the immune system, particular immunosuppression [7]. Additionally, such alterations of these factors in intracellular and intercellular homeostasis probably lead to cell death and mitochondrial dysfunction, thereby strengthening the activation of stress-related genes [3, 8]. Meanwhile, arsenic exposure through contaminated food materials is quite common in areas with high levels of arsenic in the groundwater, which is becoming an urgent issue in the field of public health. Given the increasing risk of arsenic toxicity, recently accumulating evidence supports the notion that chronic arsenic exposure is associated the suppression of immune system. Furthermore, arsenic is known to induce oxidative stress by reactive oxygen stress (ROS) generation and DNA damage and increases levels of oxidative stress markers, which may affect the production of $\mathrm{T}$ cells and impair cell function. In addition, oxidative stressresponsive genes, such as ANGPTL7, NME5, and MBL2, were reduced by several folds in relation to elevated arsenic concentrations $[9,10]$. Thus, treatment with immune modulators has been shown to regulate low immune activity induced by arsenic.

Recently, a number of plant products, their active constituents and herbal agents have received great attention as antioxidants against arsenic-induced toxicity. The most abundant polyphenol in green tea, (-)-epigallocatechin-3-gallate (EGCG) (Fig. 1), is a potent antioxidant and exhibits extensive pharmacological activity including antioxidative, antiinflammatory, anti-cancer and immunomodulatory properties [11-14]. The antioxidative activity of EGCG plays a crucial role against the above mentioned disease. It has been reported in the literature that EGCG regulates the function of T cells in autoimmunity and transplantation [15]. Further studies have confirmed that EGCG modulates the functions of dendritic cells after ultraviolet A and B irradiation and prevents the immune suppression induced by ultraviolet radiation [16]. Our recent study showed that EGCG can protect cardiac tissue against the cardiotoxicity induced by arsenic [17]. However, the effects of EGCG on the immune dysfunction induced by arsenic have not been investigated. The present study has therefore been carried out to understand the protective role of EGCG against arsenicinduced inflammation, immunotoxicity and apoptosis in mice.

\section{Materials and Methods}

\section{Ethics statement}

All animal experiments were performed according to institutional ethical committee guidelines and approved by the Medical Ethics Committee of Hunan Normal University (Grade II, Certificate No. 2015A054, Hunan Normal University) and were in accordance with the National Institutes of Health Regulations for the Care and Use of Animals. All efforts were made to minimize suffering.

Drug preparation

EGCG and $\mathrm{NaAsO}_{2}$, with a purity of 98\%,were purchased from Sigma Aldrich Corporation (Shanghai, China). A stock suspension was prepared with distilled water and stored at $4^{\circ} \mathrm{C}$ for two days (concentration: $50 \mathrm{mg} / \mathrm{mL}$ ). Throughout all the experiments, the characteristics of all the drugs were unchanged. 
Yu et al.: (-)-Epigallocatechin-3-Gallate Attenuates Arsenic-Induced Inflammation and Apoptosis

Animals and pharmacological treatment in vivo Male BALB/c mice $(15 \pm 2 \mathrm{~g})$ at 8 weeks of age were maintained in our animal house under standard conditions. They were fed with standard rodent pellet chow and water ad libitum. Our animal house and breeding facility are registered with the Committee for the Purpose of Control and Supervision of Experiments on Animals (CPCSEA); Government of China and CPCSEA guidelines were followed. The mice were randomly divided into four groups with 10 animals/group. Arsenic was dissolved in distilled water and administered by

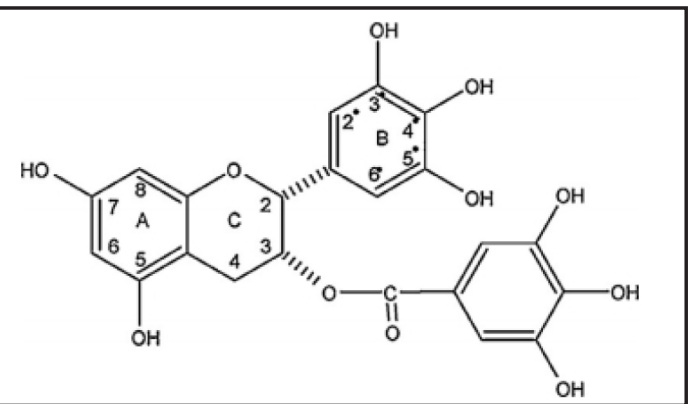

Fig. 1. Structure of (-)-epigallocatechin-3-gallate (EGCG). gavage. EGCG was also suspended in distilled water and given by gavage. Both of the treatments (arsenic and EGCG) were given by interval. There was a gap of $6 \mathrm{~h}$ between the first arsenic treatment and second EGCG treatment. Treatment was given for 30 days. All animals were randomly assigned to the following groups:

Group 1-control (received vehicle only).

Group 2-toxin control (received $\mathrm{NaAsO}_{2}$ orally at a dose of $10 \mathrm{mg} / \mathrm{kg}$ body weight, per os daily for 30 days).

Group 3-NaAsO 2 (10 mg/kg body weight, per os daily for 30 days) followed by EGCG (10 mg/kg body weight, per os daily for 30 days).

Group 4- EGCG (10 mg/kg body weight, per os daily for 30 days).

\section{Blood/tissue collection}

Blood/tissues were collected as previously described [18]. At the end of the experimental period (30 days), a set of animals were sacrificed by cervical dislocation. In another set, blood was quickly collected by heart puncture for the separation of serum. For the assessment of different inflammatory markers, the thymus and spleen were isolated from mice as previously described [7].

The thymuses and spleens of five mice per group were cleaned and placed in phosphate-buffered saline (PBS, pH 7.4) and subsequently processed for measures of immunological parameters. The remaining thymus and spleen in each set were placed in ice-cold saline solution ( $0.15 \mathrm{M})$, blot-dried, weighed, and then immediately processed for use in the assessment of arsenic level in both tissues.

Preparation of thymocyte and splenocytes suspension

The dissected thymuses and spleens from mice were processed into single-cell suspensions under aseptic conditions. The suspensions were passed through stainless steel mesh and centrifuged at $200 \times \mathrm{g}$ at $4{ }^{\circ} \mathrm{C}$ for $10 \mathrm{~min}$. The thymocytes were resuspended in PBS. The splenocytes were suspended in $5.0 \mathrm{ml}$ hypotonic erythrocyte lysing solution $\left(2.42 \mathrm{~g}\right.$ Tris and $7.56 \mathrm{~g} \mathrm{NH}_{4} \mathrm{Cl}$ in $1000 \mathrm{ml}$ deionised water, $\mathrm{pH}$ adjusted to 7.2). After $5 \mathrm{~min}$ incubation followed by centrifugation, cells were resuspended in PBS, counted on a haemocytometer and then diluted with PBS to appropriate concentrations for use in immunological assays.

The spleens were dissected from male BALB/c mice (4-6 weeks old), and a single-cell suspension was prepared under aseptic conditions. The suspension was passed through $100 \mu \mathrm{m}$ stainless steel mesh, treated with $5.0 \mathrm{ml}$ hypotonic $\mathrm{NH}_{4} \mathrm{Cl}$ solution (2.42 g Tris and $7.56 \mathrm{~g} \mathrm{NH}_{4} \mathrm{Cl}$ in $1000 \mathrm{ml}$ deionised water, $\mathrm{pH}$ adjusted to 7.2) for $5 \mathrm{~min}$ at room temperature to lyse red blood cells, centrifuged and washed with FBSfree medium. The cells were suspended in complete cell culture medium (RPMI 1640 containing HEPES and 2 mM glutamine, supplemented with 10\% FBS and 1\% antibiotic-antimycotic solution). The cell density was adjusted to $1.5 \times 10^{6}$ cells $/ \mathrm{ml}$, and the viability of the freshly isolated cells was always over 95\% (trypan blue exclusion test). After cell preparation, the monitoring of various parameters was performed in the present investigation.

\section{Assay of nitric oxide levels}

Levels of nitric oxide in the serum were estimated using a nitric oxide assay kit procured commercially (Calbiochem, USA). The assay principle involves the conversion of nitrate to nitrite by the enzymatic action of nitrate reductase. The addition of 2,3-diaminonaphthalene (DAN) and sodium hydroxide converts nitrite to a fluorescent compound, 1(H)-naphthotriazole, which is measured spectrofluorometrically (excitation $430 \mathrm{~nm} / \mathrm{emission} 450 \mathrm{~nm}$ ) using a multi-well plate reader. 


\section{Cellular Physiology Cell Physiol Biochem 2017;41:1788-1800 \\ \begin{tabular}{l|l} 
and Biochemistry Published onlIne: AprII 03, 2017 & $\begin{array}{l}\text { (c) } 2017 \text { The Author(s). Published by S. Karger AG, Basel } \\
\text { www.karger.com/cpb }\end{array}$
\end{tabular}}

Yu et al.: (-)-Epigallocatechin-3-Gallate Attenuates Arsenic-Induced Inflammation and Apoptosis

Determination of oxidative stress-related enzymes

Supernatant samples from cells were assayed for the determination of oxidative stress-related enzymes (CAT: catalase, MDA: malonyldialdehyde, SOD: superoxide dismutase, GSH: glutathione) by kits using an automatic chemical analyser (7060, Hitachi, Tokyo, Japan), following the standard procedure according to previous methods [7].

Assay of inflammatory factors (IL-1 $\beta, I L-6, T N F-\alpha)$

The levels of IL-1 $\beta$, IL- 6 and TNF- $\alpha$ in the serum of mice exposed to arsenic and simultaneous treatment of arsenic and EGCG were quantified by an ELISA method using the Quantikine mouse IL-1 $\beta$, IL- 6 and TNF- $\alpha$ kit. The intensity of the colour measured was in proportion to the amount of mouse IL-1 $\beta$, IL- 6 and TNF- $\alpha$ in the sample. The levels of IL-1 $\beta$, IL- 6 and TNF- $\alpha$ were determined using a standard curve.

Assessment of $T$ and $B$ lymphocyte population in thymocytes and splenocytes

T-cell phenotyping was conducted on the basis of CD4 and CD8 surface molecules. Quadrants were positioned on FITC/PE dot plots, and $\mathrm{CD}^{+} \mathrm{CD}^{+}$(double positive; DP) and CD4- CD8 $^{-}$(double negative; DN) subpopulations were distinguished. The lymphocyte population among splenocytes was assessed based on CD3 (for T-cells) and CD19 (for B-cells) surface molecules. Assessment of T and B lymphocyte population was performed as previously described $[19,20]$. The data were analysed with Cell Quest software, and the mean fluorescence intensity was obtained by histogram statistics.

Estimation of arsenic levels in thymus and spleen

Arsenic levels in the thymuses and spleens of mice exposed to arsenic and co-treated with EGCG were estimated with an automatic fluorescence spectrometry system, the hydride system 60 atomic absorption spectrophotometer (HSAAS, ZEEnit 700), as previously described [19]. Briefly, $1 \mathrm{ml}$ of concentrated nitric acid was added to $100 \mathrm{mg}$ of tissue, followed by $1 \mathrm{ml}$ of perchloric acid. The sample was then digested over a sand bath until the solution became yellow in colour. If the colour of the digest was brown, more nitric acid and perchloric acid were added, and the oxidation was repeated. The digest was diluted to a predetermined volume with deionized water. Aliquots of this were used to estimate the quantity of arsenic using an atomic absorption spectrophotometer. A calibration curve was constructed by adding known standard amounts of arsenic to calculate arsenic levels in the thymus and spleen.

Measurement of ROS production

Measurement of mitochondrial ROS was performed as previously described [21, 22]. Thymus cells from each group were suspended in PBS and incubated with $50 \mu \mathrm{M}$ 2',7'-dichlorofluorescin diacetate (DCFHDA) in modified Krebs solution (135 mM NaCl, $5.9 \mathrm{mM} \mathrm{KCl}, 1.5 \mathrm{mM} \mathrm{CaCl}, 1.2 \mathrm{mM} \mathrm{MgCl}, 11.5 \mathrm{mM}$ glucose, 11.6 mM HEPES, pH 7.4) supplemented with 0.1\% bovine serum albumin and 0.02\% Pluronic F-127 at 37 ${ }^{\circ} \mathrm{C}$ for $1 \mathrm{~h}$ in the dark at room temperature. ROS generation was recorded at excitation wavelength $488 \mathrm{~nm}$ and emission wavelength $525 \mathrm{~nm}$ using fluorescence microscopy.

\section{Measurement of mitochondrial membrane potential}

The thymus and spleen cells were washed twice with PBS, scraped from the dishes, and suspended in $1 \mathrm{ml}$ of cold isolation buffer. The cells were homogenized using a glass homogenizer. The homogenate was centrifuged at $1330 \times \mathrm{g}$ for $5 \mathrm{~min}$ at $4{ }^{\circ} \mathrm{C}$. The supernatants were centrifuged at $21,200 \times \mathrm{g}$ for $10 \mathrm{~min}$ at 4 ${ }^{\circ} \mathrm{C}$.The pellet was suspended in a 15\% Percoll solution, and aliquots were layered onto discontinuous Percoll gradients (23\% over $40 \%$ ) and then centrifuged for $15 \mathrm{~min}$ at $30,700 \times \mathrm{g}$ at $4^{\circ} \mathrm{C}$. The dense band of material at the interface between the $23 \%$ and $40 \%$ Percoll layers was collected,diluted 1:4 in fresh isolation buffer, and then centrifuged for $10 \mathrm{~min}$ at $16,700 \times \mathrm{g}$ at $4^{\circ} \mathrm{C}$. The pellet was resuspended in $2 \mathrm{ml}$ of isolation buffer and centrifuged again for $10 \mathrm{~min}$ at $6,900 \times \mathrm{g}$. The mitochondrial pellet was suspended in $100 \mathrm{ml}$ of PBS and used to measure mitochondrial membrane potential $(\Delta \psi \mathrm{m})$. For the detection of mitochondrial $\Delta \psi \mathrm{m}$, cells were incubated with $\mathrm{Rh} 123$ (5 $\mathrm{\mu g} / \mathrm{ml}$ final concentration) for $60 \mathrm{~min}$ in the dark at $37^{\circ} \mathrm{C}$, harvested and suspended in PBS. Mitochondrial $\Delta \psi \mathrm{m}$ was measured by the fluorescence intensity.

\section{Assay of caspase-3 activity}

The activity of caspase-3 in thymocytes was measured using the CaspACE TM Assay System (fluorometric kit) according to the manufacturer's instructions. For the assay, the fluorogenic substrates for caspase-3 were labelled with the fluorochrome AMC. AMC was released from these substrates on cleavage 


\section{Cellular Physiology Cell Physiol Biochem 2017;41:1788-1800

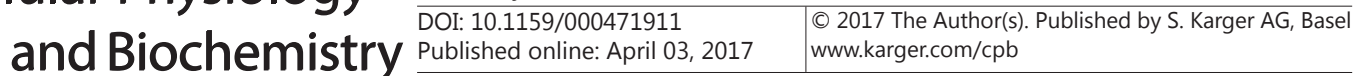 \\ Yu et al.: (-)-Epigallocatechin-3-Gallate Attenuates Arsenic-Induced Inflammation and Apoptosis}

by caspase- 3 . The activity ofcaspase- 3 was determined by monitoring the fluorescence produced by free AMC using a GloMax 20/20n Luminometer (Promega, Madison, WI, USA) at 360/460 nm.

\section{Detection of apoptotic and necrotic cells}

The distribution of apoptotic and necrotic cells was analysed by annexin V binding and PI uptake following a previously described procedure. Briefly, thymocytes were suspended in $1 \mathrm{ml}$ binding buffer $(1 \times)$, an aliquot of $100 \mu \mathrm{l}$ was incubated with $5 \mu \mathrm{l}$ annexin V-FITC and $10 \mu \mathrm{l}$ PI for $15 \mathrm{~min}$ in the dark at room temperature, and $400 \mu \mathrm{l}$ binding buffer $(1 \times)$ was added to each sample. The FITC and PI fluorescence were measured through FL-1 (530 $\mathrm{nm})$ andFL-2 filters (585 $\mathrm{nm})$, respectively.

\section{Statistical analysis}

All assays were repeated at least three times independently. All data are expressed as the mean \pm SEM. Data were analysed using one-way analysis of variance (ANOVA) followed by a Newman-Keuls test for multiple pairwise comparisons among the groups. Statistical significance was defined as $P<0.05$.

\section{Results}

Effect of EGCG on nitric oxide levels

It has been reported that the NO level indicates an impaired antioxidative defence mechanism in the case of an arsenic-related oxidative injury. To investigate the changes of oxidative stress, we measured the levels of nitric oxide in the serum. As shown in Figure 2, exposure to arsenic was associated with an increase in the level of nitric oxide level compared to the control group. Administration of EGCG significantly decreased the level of nitric oxide in the serum compared with animals treated with arsenic alone. No significant effect was observed in treatment with EGCG alone compared with the control group.

Effect of EGCG on $\mathrm{NaAsO}_{2}$-induced oxidative stress and antioxidant markers in mice

To assess the level of oxidative damage to the biological membrane, the activity levels of SOD, CAT and GSH were measured. As shown in Figure 3, the activity levels of SOD, CAT and $\mathrm{GSH}$ in $\mathrm{NaAsO}_{2}$-treated mice decreased significantly, and the content of MDA increased. After treatment with EGCG, all of the abovementioned results were reversed. These results collectively suggested that EGCG could attenuate $\mathrm{NaAsO}_{2}$-induced oxidative stress.

EGCG decreases the release of IL-1 $\beta, I L-6$ and TNF- $\alpha$ in the serum of mice

IL-1 $\beta$, IL- 6 and TNF- $\alpha$ are of great importance in organ physiology and pathophysiology. Excessive release of inflammatory factors affects cellular immune responses, resulting in immunosuppression. To investigate whether IL-1 $\beta$, IL- 6 and TNF- $\alpha$ were involved in the effects of EGCG on $\mathrm{NaAsO}_{2}$-induced inflammation, these inflammatory factors were tested. As

Fig. 2. Effect of EGCG on nitric oxide levels. Compared with the control group, ${ }^{a} P<0.05$; compared with the arsenic-treated group, ${ }^{b} P<0.05$. Values are expressed as the mean \pm SEM of five animals in each group.

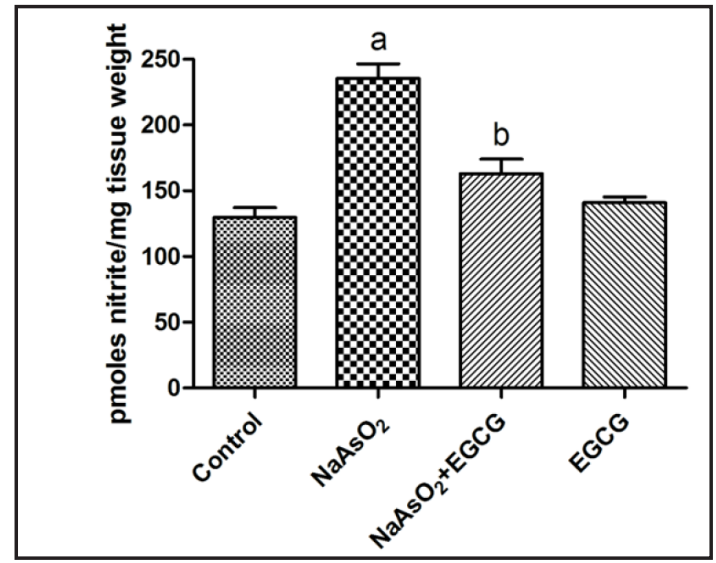


Fig. 3. Effect of EGCG on biochemical changes in mice. Compared with the control group, ${ }^{\mathrm{a}} \mathrm{P}<0.05$; compared with the arsenic-treated group, $\quad{ }^{\mathrm{b}} P<0.05$. Values are expressed as the mean \pm SEM of five animals in each group. A: SOD; B: GSH; C: CAT; D: MDA.
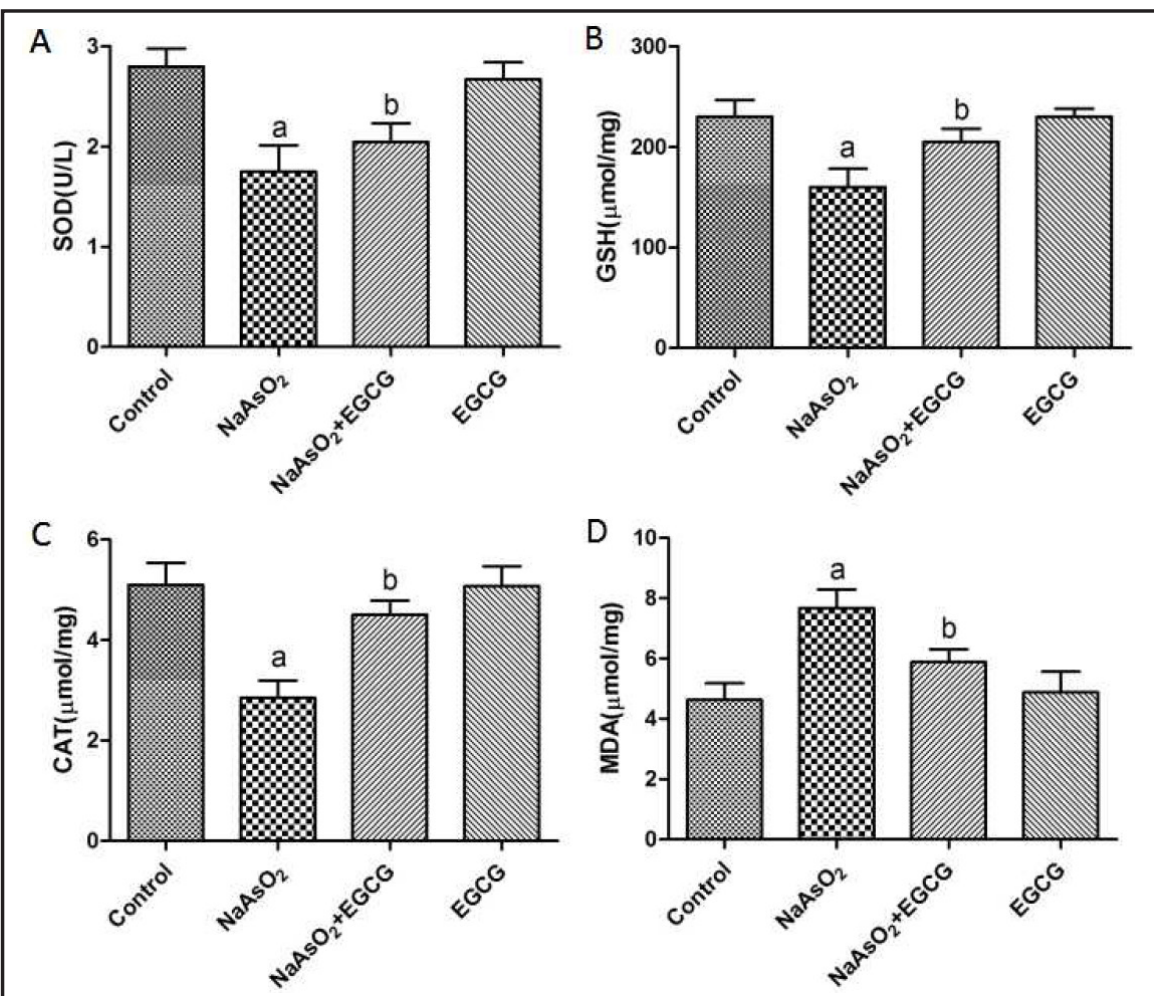

Fig. 4. EGCG decreases the release of IL-1 $\beta$, IL- 6 and TNF- $\alpha$ in the serum of mice. Compared with the control group, ${ }^{\text {a }} P<0.05$; compared with the arsenic-treated group, $\quad{ }^{\mathrm{b}} P<0.05$. Values are expressed as the mean \pm SEM of five animals in each group.
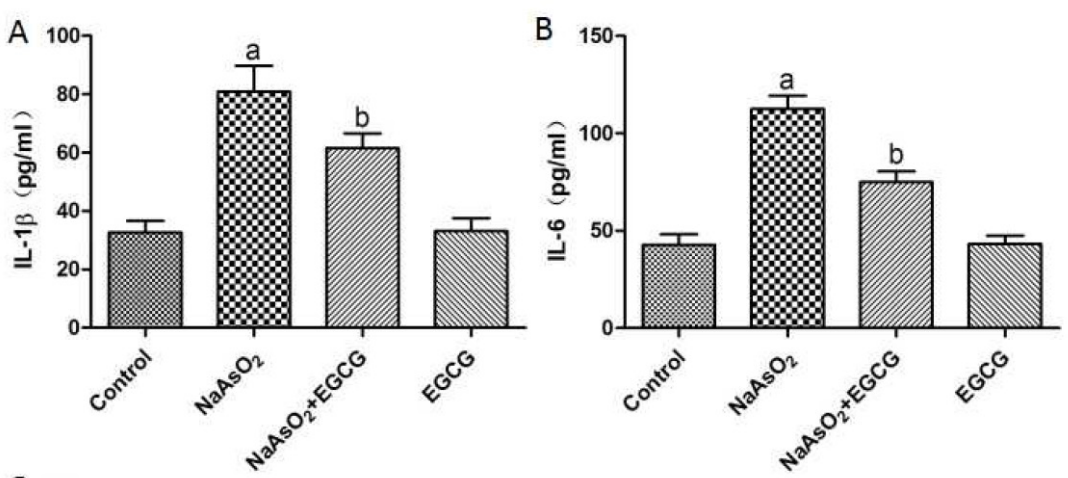

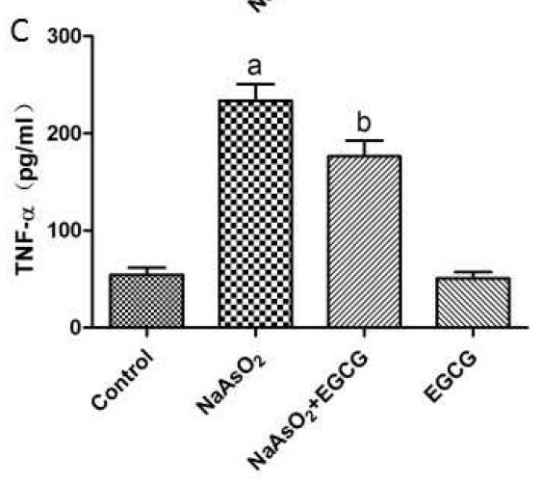

depicted in Figure 4, the present study showed that exposure to $\mathrm{NaAsO}_{2}$ causes a significant increase in the levels of IL- $1 \beta$, IL- 6 and TNF- $\alpha$. In contrast, the release of IL-1 $1 \beta$, IL- 6 and TNF- $\alpha$ by $\mathrm{NaAsO}_{2}$ was suppressed by pretreatment with EGCG in mice. These results collectively suggested that EGCG could attenuate $\mathrm{NaAsO}_{2}$-induced inflammation (Fig. 4).

\section{KARGER}


Yu et al.: (-)-Epigallocatechin-3-Gallate Attenuates Arsenic-Induced Inflammation and Apoptosis

Fig. 5. Effect of EGCG on $\mathrm{T}$ and $\mathrm{B}$ lymphocyte populations in thymocytes and splenocytes of mice. A: The ratio of CD4(Th) (\%); B: The ratio of $\mathrm{CD} 4(\mathrm{Tc})(\%)$; $\mathrm{C}$ : The ratio of $\mathrm{CD} 4(\mathrm{Th}) /$ CD8(Tc) (\%); D: The ratio of $\mathrm{CD} 3(\mathrm{~T})(\%)$; $\mathrm{E}$ : The ratio of CD19(B) (\%). Compared with the control group, a $P<0.05$; compared with the arsenic-treated group, ${ }^{\text {b }} P<0.05$. Values are expressed as the mean \pm SEM of five animals in each group.
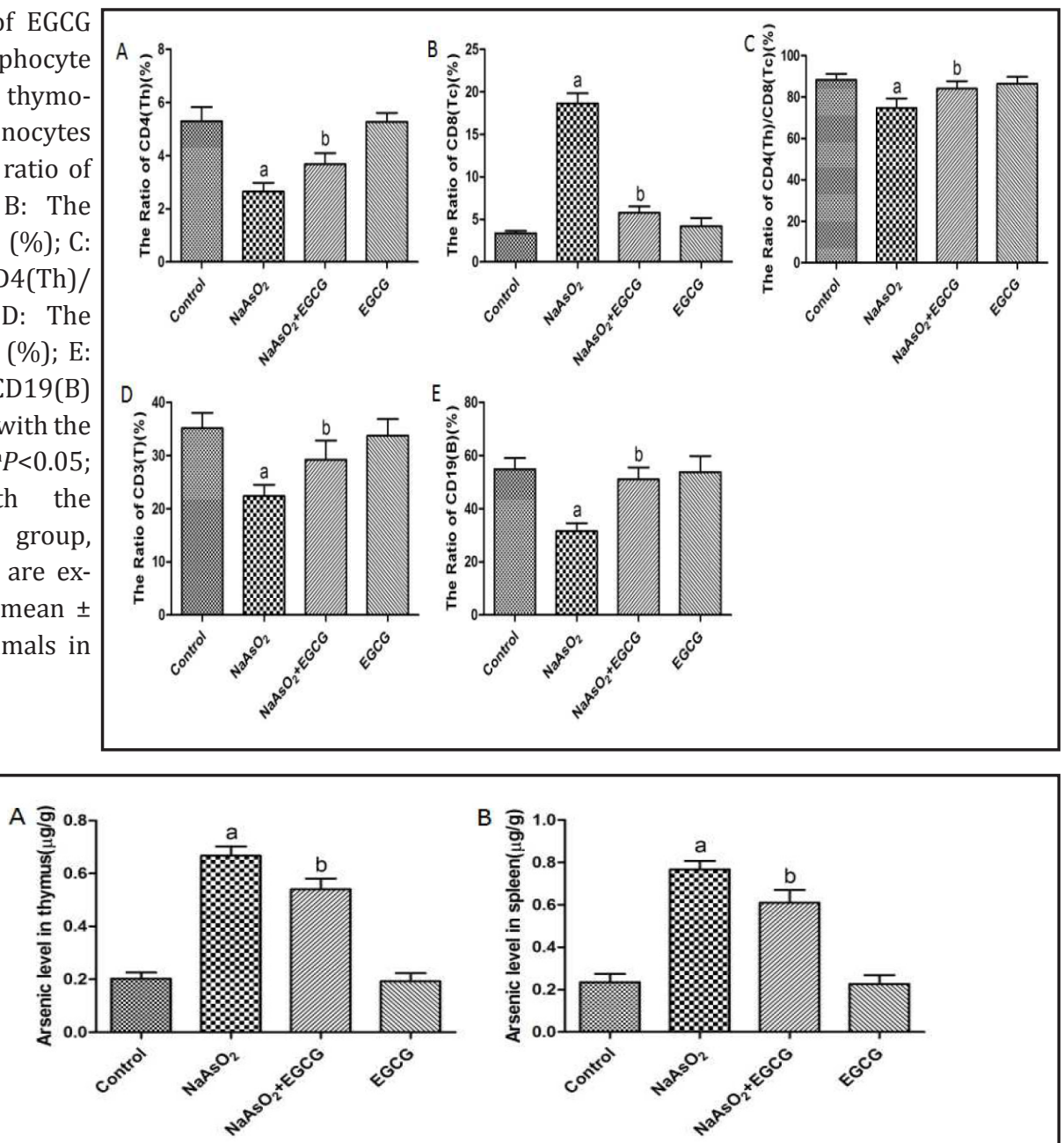

Fig. 6. Effect of EGCG on arsenic levels in thymus and spleen of mice. A: Arsenic level in the thymus; B: Arsenic level in the spleen. Compared with the control group, ${ }^{a} P<0.05$; compared with the arsenic-treated group, ${ }^{\mathrm{b}} P<0.05$. Values are expressed as the mean \pm SEM of five animals in each group.

Effect of EGCG on T and B lymphocyte population in thymocytes and splenocytes of mice

It has been reported that arsenic exposure in mammals impairs the activity of lymphocytes, monocytes, and macrophages and affects cellular immune responses, resulting in immunosuppression. To investigate the effects of arsenic on thymocytes and splenocytes in mice, the T and B lymphocyte populations were assessed. As indicated in Figure 5, arsenic exposure increased the relative frequency of the CD8 (Tc)-positive cell subpopulation from 2.8 to $18.9 \%$ and decreased the ratio of CD4 (Th)-positive cells from 5.2 to $2.7 \%$. These changes were reversed following simultaneous treatment with EGCG. Both the CD8 and CD4 cells types came close to the control group at $2.5 \%$ and $3.4 \%$, respectively, compared with the $\mathrm{NaAsO}_{2}$-treated group. No significant effects on CD8 and CD4 cell ratios were observed in EGCG treatment alone compared with the control group.

Compared with controls, the arsenic-treated group showed a significant decrease in T (CD3)-cells from $32.5 \%$ to $19.2 \%$ and in B (CD19)-cells from 55.1 to $32.5 \%$, whereas simultaneously treatment with arsenic and EGCG restored the proportions to $29.3 \%$ and $49.5 \%$, respectively. No significant effects on T (CD3)- and B (CD19)-cells were observed in mice treated with EGCG alone compared with the control group. 


\section{Cellular Physiology and Biochemistry

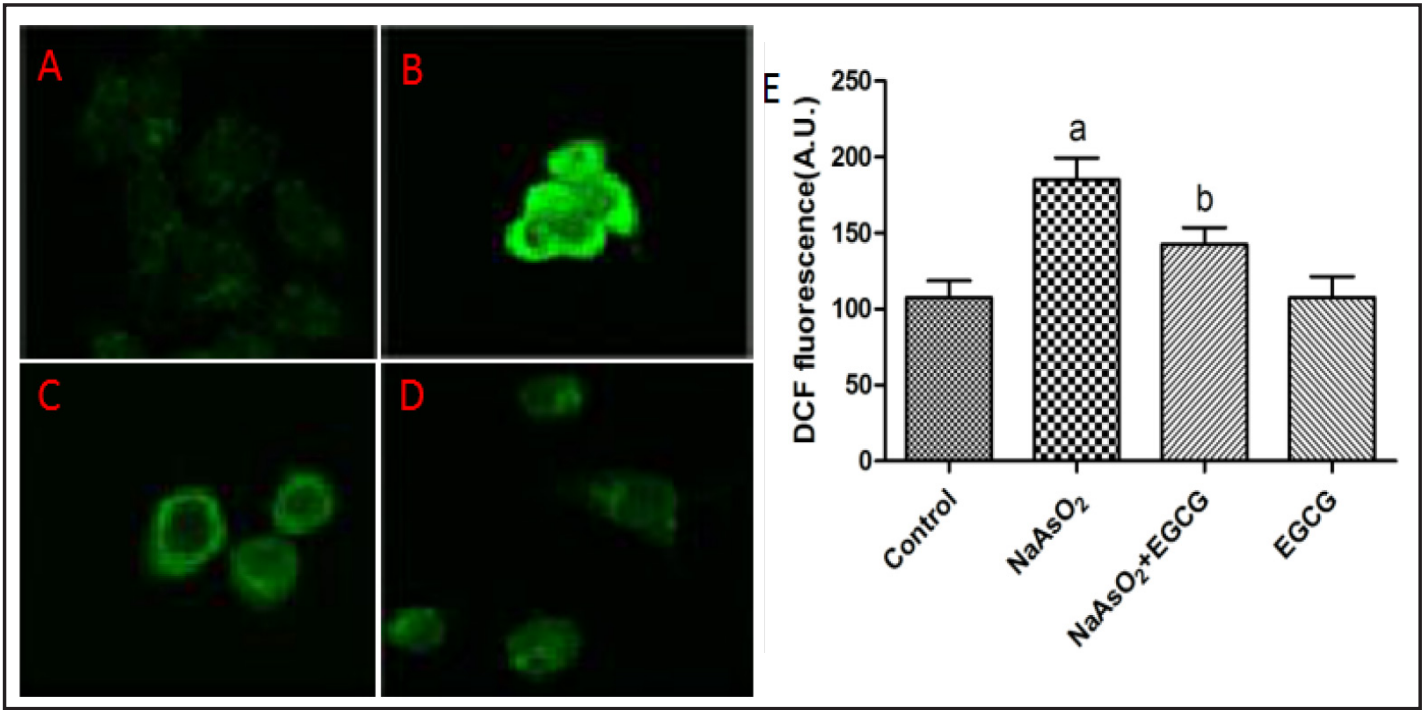

Fig. 7. Effect of EGCG on $\mathrm{NaAsO}_{2}$-induced ROS generation in the thymus of mice. Compared with the control group, ${ }^{a} P<0.05$; compared with the arsenic-treated group, ${ }^{b} P<0.05$. Values are expressed as the mean \pm SEM of five animals in each group.

\section{Effect of EGCG on arsenic levels in thymus and spleen of mice}

To further confirm the effect of EGCG on $\mathrm{NaAsO}_{2}$ in the thymus and spleen of mice, the levels of arsenic were determined by spectrophotometry. As shown in Figure 6, there existed a significant increase in the tissue levels of arsenic in animals exposed to arsenic for 30 days compared with the control group. Treatment with EGCG decreased the levels of arsenic in the thymus and spleen.

\section{Effect of EGCG on $\mathrm{NaAsO}_{2}$-induced ROS generation}

Arsenic has been found to be associated with increased generation of $\mathrm{ROS}$. $\mathrm{NaAsO}_{2}$ induced ROS generation is supposed to be one of the major contributors to apoptosis and injury related to different organs. To determine whether pretreatment with EGCG mitigated $\mathrm{NaAsO}_{2}$-induced oxidative stress, total ROS were measured by incubating the thymus with $10 \mu \mathrm{M}$ DCF-AM fluorophore. Our data demonstrated that EGCG attenuated the $\mathrm{NaAsO}_{2}$ induced increase in DCF fluorescence in the thymus. As shown in Figure 7, treatment with EGCG significantly inhibited the elevated intracellular concentration of ROS compared with the $\mathrm{NaAsO}_{2}$-treated thymus.

\section{Effect of EGCG on mitochondrial membrane potential}

Loss of mitochondrial membrane potential $(\Delta \psi \mathrm{m})$ is a common index of mitochondrial damage that results from the surplus generation of ROS. To investigate the direct effect of EGCG on $\Delta \psi \mathrm{m}$, the $\Delta \psi \mathrm{m}$ was measured after incubation with Rh 123. As shown in Figure 8A, $\mathrm{NaAsO}_{2}$ exposure caused a decrease in $\Delta \psi \mathrm{m}$. EGCG increased the $\Delta \psi \mathrm{m}$ in thymus compared with mice treated with arsenic. No effect on $\Delta \psi \mathrm{m}$ was observed in mice treated with EGCG alone compared with the control group.

\section{Effect of EGCG on $\mathrm{NaAsO}_{2}$-induced caspase-3 activation}

Activation of the caspase cascade is crucial in the initiation of apoptosis in diverse biological processes. To investigate whether caspase-3 was involved in the effects of EGCG on $\mathrm{NaAsO}_{2}$-induced cytotoxicity, the activity of caspase- 3 was assessed. The present study showed that caspase- 3 activity significantly increased after treatment with $\mathrm{NaAsO}_{2}$. In contrast, activation of caspase- 3 by $\mathrm{NaAsO}_{2}$ was suppressed in the thymus of animals pretreated with EGCG (Fig. 8B).

\section{KARGER}



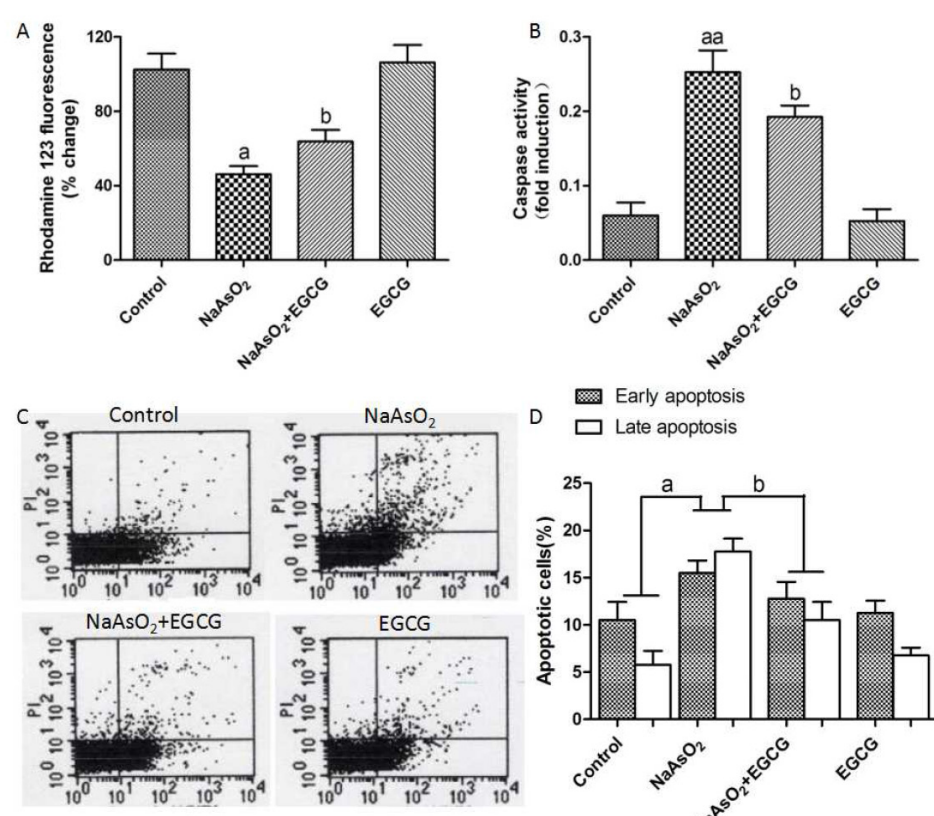

D Early apoptosis

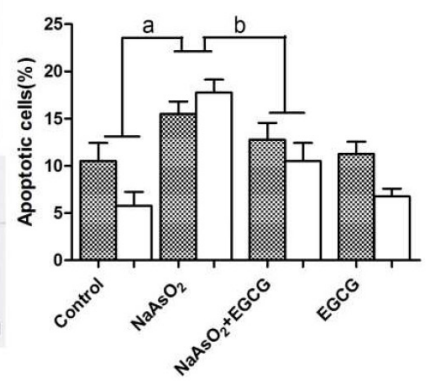

Fig. 8. Effect of EGCG on mitochondrial membrane potential, cell apoptosis and oxidative stress in thymus of mice. A: Determination of mitochondrial membrane potential; B: Activity of caspase-3; C: Flow cytometry analysis of annexinV-FITC/PI staining. D: Quantification histograms indicate the percentages of cells in the early (annexin V-FITC positive and PI negative) and late stages of cell death.Compared with the control group, ${ }^{a} P<0.05$, aa $P<0.05$; compared with the arsenic-treated group, ${ }^{b} P<0.05$. Values are expressed as the mean \pm SEM of five animals in each group.

Effect of EGCG on apoptotic and necrotic cells of the thymus in $\mathrm{NaAsO}_{2}$-treated mice

It is reported that there exists a progressive increase in apoptotic and necrotic cell death in thymocytes and splenocytes. Arsenic exposure caused an increase in apoptotic and necrotic cells compared with the control group. Treatment with EGCG decreased the number of apoptotic and necrotic cells in the thymus compared with mice treated with arsenic alone (Fig. 8C, D).

\section{Discussion}

The study presented herein clearly demonstrated the anti-inflammatory and antiapoptosis properties of EGCG against $\mathrm{NaAsO}_{2}$-induced immunotoxicity in vivo. Our data showed that treatment with EGCG significantly attenuates the enhancement of oxidative stress and $\mathrm{NaAsO}_{2}$-related immunotoxicity (including dysfunction of CD8+(Tc) cells, $\mathrm{CD} 4+(\mathrm{Th})$ cells, $\mathrm{T}(\mathrm{CD} 3)$ and $\mathrm{B}(\mathrm{CD} 19)$ cells), suppresses apoptosis of thymocytes and splenocytes, and inhibits the release of inflammatory factors in mice. Importantly, this study has verified that reduction of ROS production and decreased activation of caspase- 3 were associated with the protective effects of EGCG. These results provide insight into the mechanisms by which EGCG acts a potential therapeutic prescription to ameliorate the immunotoxicity induced by $\mathrm{NaAsO}_{2}$.

Chronic arsenic exposure through contaminated drinking water causes immunosuppression and affects the secretion of a variety of cytokines in the population [2, 23, 24]. Mitochondria are regarded as the main targets of arsenic toxicity [25]. In addition, it has been reported that these cytokines, including TNF- $\alpha$, IL- $1 \beta$ and IL- 6 , are involved in the generation of free radicals through the mitochondrial respiratory chain reaction in response to arsenic toxicity $[26,27]$. These pro-inflammatory mediators are involved in various biological 
and cellular changes including growth factors, transcription factors and activation of proapoptotic proteins. Arsenic exposure weakens the activity of immune cells(lymphocytes, monocytes, and macrophages) and further influences cellular immune responses, resulting in immunosuppression [28]. Meanwhile, arsenic can decrease CD4+ cell numbers from the spleen, suppress contact hypersensitivity responses and increase CD8+ cell numbers. Accumulating evidence has shown that arsenic exposure interferes with the activation of $\mathrm{T}$ cells and inhibits immune cell migration in animal models [29]. The results of the present study suggested that arsenic exposure significantly increased the levels of TNF- $\alpha$, IL-1 $\beta$ and IL- 6 compared with controls. Arsenic exposure increased the relative frequency of the CD8+ cell subpopulation and decreased the frequency of CD4+ cells. In addition, arsenic significantly decreased $\mathrm{T}$ (CD3) and B(CD19) cells compared with controls. These changes may cause cellular dysfunction due to the development of inflammatory reactions and the secretion of a variety of inflammatory cytokines. Several lines of study have also shown that supplementation of dietary antioxidants may reverse arsenic-induced oxidative damage andimmunotoxicity [30]. Accumulating evidence has revealed that EGCG, as a potent antioxidative agent, can inhibit inflammation and enhance the survival of disc cells in oxidative stress [31]. The anti-inflammatory effects of EGCG on radiculopathic pain have also been investigated in vitro and may benefit from its inhibitory effect on the overexpression of pro-inflammatory mediators [13, 32]. Given the inhibition of immune cell-derived cellular functions by arsenic exposure and the antioxidative and anti-inflammatory properties of EGCG in antagonizing increased secretion of inflammatory mediators, simultaneous exposure to EGCG has been found to be beneficial in increasing arsenic mobilization and assisting the recovery of altered biochemical levels during chemical therapy. In the present study, simultaneous treatment with EGCG significantly restored the alterations in CD8+ and CD4+ cells and ameliorated the damage in the $\mathrm{B}$ and $\mathrm{T}$ cell subpopulations in the thymus and spleen of mice. These findings suggested that EGCG could modulate $\mathrm{NaAsO}_{2}$-induced immunotoxicity in mice.

Numerous studies have shown that EGCG possesses extensive pharmacological actions in various diseases, including immunosuppression in mice [18]. It has been reported that there is a positive correlation between the application of EGCG and reduction of heavy metal poisoning-related risk in both epidemiological and experimental studies. These actions of EGCG originate partially from its antioxidant properties. Moreover, EGCG can also inhibit oxidative stress by increasing the activity of endogenous antioxidant enzymes and protein expression, decreasing apoptosis rate and attenuating ROS production. In the present study, arsenic treatment decreased the level of NO and the activity of SOD, CAT, GSH and increased the content of MDA in $\mathrm{NaAsO}_{2}$-treatedmice. These indices are well proven as special markers in the diagnosis of arsenic-related organ toxicity. Administration of EGCG apparently decreases the levels of these enzymes in the thymus of mice. These findings suggested that EGCG could attenuate oxidative stress in $\mathrm{NaAsO}_{2}$-treatedmice.

Arsenic has been shown to be a strong inducer of apoptosis in various models through excessive production of ROS, decreased mitochondrial membrane potential, activation of caspase, increased fragmentation of DNA and impairment of T-cell activity via up-regulation of immune and stress response genes associated with increased production of ROS, which might be involved in the apoptosis and necrosis that it induces in immune cells [10, 33-35]. Earlier reports demonstrated a strong link between immunotoxicity and formation of reactive oxygen species (ROS), which is related to arsenic exposure [36]. Generation of ROS induced by arsenic is involved in the regulation of the initiation of apoptosis in the lymphocytes and is also involved in the immunotoxic response. Given the important role of oxidative stress in arsenic-related immunosuppression and apoptosis, ROS scavengers or antioxidants may be a promising approach for modulating the immunotoxic response. It has been reported that EGCG acts as an antioxidant and immune booster both in vivo and in vitro [37]. Thus, we speculated that EGCG might play an important role in arsenic-related disorders. In the present study, we found that arsenic caused mitochondrial damage along with an excess of ROS production and finally promoted apoptosis in thymocytes and splenocytes, which is consistent with previous studies. Supplementation with EGCG protected against the harmful 


\section{Cellular Physiology Cell Physiol Biochem 2017;41:1788-1800 \\ \begin{tabular}{l|l} 
DOI: 10.1159/000471911 & Ond Biochemistry 2017 The Author(s). Published by S. Karger AG, Basel \\
wwww.karger.com/cpb
\end{tabular} \\ Yu et al.: (-)-Epigallocatechin-3-Gallate Attenuates Arsenic-Induced Inflammation and Apoptosis}

action of free radicals and exhibited ameliorating effects on $\mathrm{NaAsO}_{2}$-induced apoptosis. EGCG, as a potent antioxidant, can enhance antioxidative activity, which increases resistance to oxidative injury invivo and in vitro [38]. In the present study, one of the most interesting observations is the ability of EGCG to reduce the concentration of arsenic in the thymus and spleen tissue, decreasing the arsenic burden in target tissues by its metal chelating properties. This action may play a crucial role in its immunoprotective effect. These findings suggest that the protective effect of EGCG against $\mathrm{NaAsO}_{2}$-induced immunotoxicity may involve its potent antioxidant activity.

\section{Conclusion}

In conclusion, the present study revealed that EGCG could attenuate $\mathrm{NaAsO}_{2}$-induced immunotoxicity and that the mechanism may involve its potent antioxidant capacity. These findings suggest that EGCG has clinical potential for the amelioration of $\mathrm{NaAsO}_{2}$-induced inflammation and apoptosis.

\section{Acknowledgements}

This work was supported by the Scientific and Technological Funds of Guizhou Province (J2013050 to YP Huang), the China Postdoctoral Science Foundation (2015 M582352 to YP Huang), the Scientific and Technological Funds of Hunan Province (J2016wk2034 to NH Yu) and the Scientific and Technological Funds of Hunan Province (2015JC3064 to YF Li).

\section{Disclosure Statement}

There is no conflict of interest.

\section{References}

1 Dutta M, Ghosh D, Ghosh AK, Bose G, Chattopadhyay A, Rudra S, Dey M, Bandyopadhyay A, Pattari SK, Mallick S, Bandyopadhyay D: High fat diet aggravates arsenic induced oxidative stress in rat heart and liver. Food Chem Toxicol 2014;66:262-277.

- Andrew AS, Jewell DA, Mason RA, Whitfield ML, Moore JH, Karagas MR: Drinking-water arsenic exposure modulates gene expression in human lymphocytes from a u.S. Population. Environ Health Perspect 2008;116:524-531.

-3 Srivastava P, Yadav RS, Chandravanshi LP, Shukla RK, Dhuriya YK, Chauhan LK, Dwivedi HN, Pant AB, Khanna VK: Unraveling the mechanism of neuroprotection of curcumin in arsenic induced cholinergic dysfunctions in rats. Toxicol Appl Pharmacol 2014;279:428-440.

4 Islam LN, Nabi AH, Rahman MM, Zahid MS: Association of respiratory complications and elevated serum immunoglobulins with drinking water arsenic toxicity in human. J Environ Sci Health A Tox Hazard Subst Environ Eng 2007;42:1807-1814.

5 Marnett LJ, Riggins JN, West JD: Endogenous generation of reactive oxidants and electrophiles and their reactions with DNA and protein. J Clin Invest 2003;111:583-593.

6 Palmieri MA, Tasat DR, Molinari BL: Oxidative metabolism of lung macrophages exposed to sodium arsenite. Toxicol In Vitro 2007;21:1603-1609.

7 Singh MK, Yadav SS, Yadav RS, Chauhan A, Katiyar D, Khattri S: Protective effect of emblica-officinalis in arsenic induced biochemical alteration and inflammation in mice. Springerplus 2015;4:438.

- 8 Liu SX, Athar M, Lippai I, Waldren C, Hei TK: Induction of oxyradicals by arsenic: Implication for mechanism of genotoxicity. Proc Natl Acad Sci U S A 2001;98:1643-1648. 


\section{Cellular Physiology Cell Physiol Biochem 2017;41:1788-1800 \begin{tabular}{ll|l} 
and BOI: 10.1159/000471911 & $\begin{array}{l}\text { () } 2017 \text { The Author(s). Published by S. Karger AG, Basel } \\
\text { www.karger.com/cpb }\end{array}$ \\
\hline
\end{tabular}}

Yu et al.: (-)-Epigallocatechin-3-Gallate Attenuates Arsenic-Induced Inflammation and Apoptosis

-9 Dutta K, Prasad P, Sinha D: Chronic low level arsenic exposure evokes inflammatory responses and DNA damage. Int J Hyg Environ Health 2015;218:564-574.

10 Mao J, Yang J, Zhang Y, Li T, Wang C, Xu L, Hu Q, Wang X, Jiang S, Nie X, Chen G: Arsenic trioxide mediates hapi microglia inflammatory response and subsequent neuron apoptosis through p38/jnk mapk/stat3 pathway. Toxicol Appl Pharmacol 2016;303:79-89.

11 Chen J, Du L, Li J, Song H: Epigallocatechin-3-gallate attenuates cadmium-induced chronic renal injury and fibrosis. Food Chem Toxicol 2016;96:70-78.

$\checkmark 12$ Miltonprabu S, Thangapandiyan S: Epigallocatechin gallate potentially attenuates fluoride induced oxidative stress mediated cardiotoxicity and dyslipidemia in rats. J Trace Elem Med Biol 2015;29:321-335.

13 Wang QM, Wang H, Li YF, Xie ZY, Ma Y, Yan JJ, Gao YF, Wang ZM, Wang LS: Inhibition of emmprin and mmp-9 expression by epigallocatechin-3-gallate through 67-kda laminin receptor in pma-induced macrophages. Cell Physiol Biochem 2016;39:2308-2319.

14 Yang WS, Moon SY, Lee MJ, Park SK: Epigallocatechin-3-gallate attenuates the effects of tnf-alpha in vascular endothelial cells by causing ectodomain shedding of tnf receptor 1 . Cell Physiol Biochem 2016;38:1963-1974.

15 Hushmendy S, Jayakumar L, Hahn AB, Bhoiwala D, Bhoiwala DL, Crawford DR: Select phytochemicals suppress human t-lymphocytes and mouse splenocytes suggesting their use in autoimmunity and transplantation. Nutr Res 2009;29:568-578.

16 Jin SL, Zhou BR, Luo D: Protective effect of epigallocatechin gallate on the immune function of dendritic cells after ultraviolet b irradiation. J Cosmet Dermatol 2009;8:174-180.

-17 Sun TL, Liu Z, Qi ZJ, Huang YP, Gao XQ, Zhang YY: (-)-epigallocatechin-3-gallate (egcg) attenuates arsenicinduced cardiotoxicity in rats. Food Chem Toxicol 2016;93:102-110.

- 18 Singh MK, Yadav SS, Gupta V, Khattri S: Immunomodulatory role of emblica officinalis in arsenic induced oxidative damage and apoptosis in thymocytes of mice. BMC Complement Altern Med 2013;13:193.

19 Pathak N, Khandelwal S: Cytoprotective and immunomodulating properties of piperine on murine splenocytes: An in vitro study. Eur J Pharmacol 2007;576:160-170.

20 Pathak N, Khandelwal S: Immunomodulatory role of piperine in cadmium induced thymic atrophy and splenomegaly in mice. Environ Toxicol Pharmacol 2009;28:52-60.

21 Morita T, Okada M, Hara Y, Yamawaki H: Addition of adult serum improves endothelium-dependent relaxation of organ-cultured rat mesenteric artery via inhibiting mitochondrial reactive oxygen species. Vascul Pharmacol 2013;58:105-111.

-22 Archana PR, Nageshwar Rao B, Ballal M, Satish Rao BS: Thymol, a naturally occurring monocyclic dietary phenolic compound protects chinese hamster lung fibroblasts from radiation-induced cytotoxicity. Mutat Res 2009;680:70-77.

23 Biswas R, Ghosh P, Banerjee N, Das JK, Sau T, Banerjee A, Roy S, Ganguly S, Chatterjee M, Mukherjee A, Giri AK: Analysis of t-cell proliferation and cytokine secretion in the individuals exposed to arsenic. Hum Exp Toxicol 2008;27:381-386.

24 Ferrario D, Croera C, Brustio R, Collotta A, Bowe G, Vahter M, Gribaldo L: Toxicity of inorganic arsenic and its metabolites on haematopoietic progenitors "in vitro": Comparison between species and sexes. Toxicology 2008;249:102-108.

-25 Gong X, Ivanov VN, Davidson MM, Hei TK: Tetramethylpyrazine (tmp) protects against sodium arseniteinduced nephrotoxicity by suppressing ros production, mitochondrial dysfunction, pro-inflammatory signaling pathways and programed cell death. Arch Toxicol 2015;89:1057-1070.

26 Ingawale DK, Mandlik SK, Naik SR: Models of hepatotoxicity and the underlying cellular, biochemical and immunological mechanism(s): A critical discussion. Environ Toxicol Pharmacol 2014;37:118-133.

27 Prabu SM, Muthumani M: Silibinin ameliorates arsenic induced nephrotoxicity by abrogation of oxidative stress, inflammation and apoptosis in rats. Mol Biol Rep 2012;39:11201-11216.

28 Sakurai T, Kaise T, Matsubara C: Inorganic and methylated arsenic compounds induce cell death in murine macrophages via different mechanisms. Chem Res Toxicol 1998;11:273-283.

29 Song MM, Fang S, Tanaka S, Sugiyama K, Kiyomi A, Kato R, Onda K, Yuan B, Takagi N, Hu X, Hirano T: Effects of arsenic disulfide on proliferation, cytokine production, and frequencies of cd4(+), cd8(+), and regulatory t cells in mitogen-activated human peripheral blood mononuclear cells. Int Immunopharmacol 2015;29:832-838. 
Yu et al.: (-)-Epigallocatechin-3-Gallate Attenuates Arsenic-Induced Inflammation and Apoptosis

-30 Sankar P, Telang AG, Suresh S, Kesavan M, Kannan K, Kalaivanan R, Sarkar SN: Immunomodulatory effects of nanocurcumin in arsenic-exposed rats. Int Immunopharmacol 2013;17:65-70.

-31 Ahmed NA, Radwan NM, Aboul Ezz HS, Salama NA: The antioxidant effect of green tea mega egcg against electromagnetic radiation-induced oxidative stress in the hippocampus and striatum of rats. Electromagn Biol Med 2017;36:63-73.

-32 Krupkova O, Sekiguchi M, Klasen J, Hausmann O, Konno S, Ferguson SJ, Wuertz-Kozak K: Epigallocatechin 3-gallate suppresses interleukin-1beta-induced inflammatory responses in intervertebral disc cells in vitro and reduces radiculopathic pain in rats. Eur Cell Mater 2014;28:372-386.

33 Yun M, Lee D, Park MN, Kim EO, Sohn EJ, Kwon BM, Kim SH: Cinnamaldehyde derivative (cb-pic) sensitizes chemo-resistant cancer cells to drug-induced apoptosis via suppression of mdr1 and its upstream stat3 and akt signalling. Cell Physiol Biochem 2015;35:1821-1830.

-34 Xu WX, Liu SZ, Wu D, Qiao GF, Yan J: Sumoylation of the tumor suppressor promyelocytic leukemia protein regulates arsenic trioxide-induced collagen synthesis in osteoblasts. Cell Physiol Biochem 2015;37:15811591.

-35 Li C, Liu Y, Liu H, Zhang W, Shen C, Cho K, Chen X, Peng F, Bi Y, Hou X, Yang Z, Zheng Z, Wang K, Wang X, Zhang J, Zhong C, Zou H, Zhang X, Zhao S: Impact of autophagy inhibition at different stages on cytotoxic effect of autophagy inducer in glioblastoma cells. Cell Physiol Biochem 2015;35:1303-1316.

-36 Arkusz J, Stanczyk M, Lewiniska D, Stepnik M: Modulation of murine peritoneal macrophage function by chronic exposure to arsenate in drinking water. Immunopharmacol Immunotoxicol 2005;27:315-330.

-37 Katiyar SK: Skin photoprotection by green tea: Antioxidant and immunomodulatory effects. Curr Drug Targets Immune Endocr Metabol Disord 2003;3:234-242.

-38 Shen K, Feng X, Su R, Xie H, Zhou L, Zheng S: Epigallocatechin 3-gallate ameliorates bile duct ligation induced liver injury in mice by modulation of mitochondrial oxidative stress and inflammation. PLoS One 2015;10:e0126278. 